Editorial

\title{
Integration of High Voltage AC/DC Grids into Modern Power Systems
}

\section{Fazel Mohammadi}

Electrical and Computer Engineering (ECE) Department, University of Windsor, Windsor, ON N9B 1K3, Canada; fazel@uwindsor.ca or fazel.mohammadi@ieee.org

Received: 22 May 2020; Accepted: 22 May 2020; Published: 26 May 2020

Abstract: The Special Issue on "Integration of High Voltage AC/DC Grids into Modern Power Systems" is published. A total of five qualified papers are published in this Special Issue. The topics of the papers are control, protection, operation, planning, and scheduling of high voltage AC/DC grids. Twenty-five researchers have participated in this Special Issue. We hope that this Special Issue is helpful for high voltage applications.

Keywords: High Voltage AC/DC Grids; Power Systems Control; Power Systems Operation; Power Systems Optimization; Power Systems Planning; Power Systems Protection

\section{Introduction}

Electric power transmission relies on AC and DC grids. The large integration of the conventional and non-conventional energy sources and power converters into power grids has resulted in a demand for High Voltage (HV), Extra-High Voltage (EHV), and Ultra-High Voltage (UHV) AC/DC transmission grids in modern power systems [1-3]. To ensure the security, adequacy, and reliable operation of power systems, practical aspects of interconnecting HV, EHV, and UHV AC/DC grids into the electric power systems, along with their economic and environmental impacts should be considered. The stability analysis for planning and operation of HV, EHV, and UHV AC/DC grids in power systems is regarded as the other key issue in modern power systems [4,5]. Moreover, interactions between power converters and the other power electronics devices (e.g., FACTS devices) installed on the network are the other aspects of power systems that must be addressed [6]. This Special Issue aims to investigate the integration of HV, EHV, and UHV AC/DC grids into modern power systems by analyzing their control, operation, protection, dynamics, planning, reliability, and security along with considering power quality improvement, market operations, power conversion, cybersecurity, supervisory and monitoring, diagnostics, and prognostics systems.

\section{Integration of High Voltage AC/DC Grids into Modern Power Systems}

M. J. Alvi, et al. [7], in their paper entitled "Field Optimization and Electrostatic Stress Reduction of Proposed Conductor Scheme for Pliable Gas-Insulated Transmission Lines", performs the geometric and electrostatic field optimization for Flexible Gas-Insulated Transmission Lines (FGILs) regarding stranded conductors. Also, the impact of conductor irregularity on field dispersion is investigated, and a Semiconducting Film (SCF)-coated stranded conductor is suggested as a potential candidate for FGILs. Owing to the performed optimized design, an $11 \mathrm{kV}$ scaled-down model of a $132 \mathrm{kV}$ FGIL is fabricated to practically investigate the electrostatic and dielectric stresses in the FGIL through an HV experimental setup.

F. Mohammadi, et al. [8], in their paper entitled "An Improved Mixed AC/DC Power Flow Algorithm in Hybrid AC/DC Grids with MT-HVDC Systems", proposes a mixed AC/DC Power Flow (PF) algorithm for hybrid AC/DC grids with Multi-Terminal High-Voltage Direct Current (MT-HVDC) 
systems. The proposed strategy is a fast and accurate method, which is capable of optimizing the AC/DC PF calculations. Except for the high accuracy and optimized performance, considering all operational constraints and control objectives of the integration of MT-HVDC systems into the large-scale AC grids is the other contribution of this paper. The calculated results by the mixed AC/DC PF problem can be used for the planning, scheduling, state estimation, small-signal stability analyses. The mixed AC/DC PF algorithm is applied to a five-bus AC grid with a three-bus MT-HVDC system and the modified IEEE 39-bus test system with two four-bus MT-HVDC systems (in two different areas), which are all simulated in MATLAB software. To check the performance of the mixed AC/DC PF algorithm, different cases are considered.

A. H. Shojaei, et al. [9], in their paper entitled "Multi-Objective Optimal Reactive Power Planning under Load Demand and Wind Power Generation Uncertainties Using $\varepsilon$-Constraint Method", attempts to address Reactive Power Planning (RPP) as a probabilistic multi-objective problem to reduce the total cost of reactive power investment, minimize the active power losses, maximize the voltage stability index, and improve the loadability factor. The generators' voltage magnitude, the transformers tap settings, and the output reactive power of the VAR sources are considered as the main control variables. To deal with the probabilistic multi-objective RPP problem, the $\varepsilon$-constraint technique is employed. To validate the efficiency of the proposed method, the IEEE 30-bus test system is implemented in the GAMS environment under five various conditions.

Y. Cui, et al. [10], in their paper entitled "Effect of Ionic Conductors on the Suppression of PTC and Carrier Emission of Semiconductive Composites", discusses the Positive Temperature Coefficient (PTC) effects of electrical resistivity in perovskite $\mathrm{La}_{0.6} \mathrm{Sr}_{0.4} \mathrm{CoO}_{3}$ (LSC) particle-dispersed semiconductive composites of HVDC cables based on experimental results from Scanning Electron Microscopy (SEM), Transmission Electron Microscopy (TEM) and a semiconductive resistance test device.

T. T. Nguyen, et al. [11], in their paper entitled "Optimal Scheduling of Large-Scale Wind-Hydro-Thermal Systems with Fixed-Head Short-Term Model", implements a Modified Adaptive Selection Cuckoo Search Algorithm (MASCSA) for determining the optimal operating parameters of a hydrothermal system and a wind-hydro-thermal system, to minimize the total electricity generation cost from all available thermal power plants. The fixed-head short-term model of hydropower plants is taken into consideration. All hydraulic constraints, such as initial and final reservoir volumes, the upper limit and lower limit of reservoir volume, and water balance of reservoir, are seriously considered. The proposed MASCSA competes with the conventional Cuckoo Search Algorithm (CSA) and Snap-Drift Cuckoo Search Algorithm (SDCSA). Two test systems, (1) four hydropower plants and four thermal power plants with valve effects over one day with twenty-four one-hour subintervals, and (2) four hydropower plants, four thermal power plants, and two wind farms with the rated power of $120 \mathrm{MW}$ and $80 \mathrm{MW}$ over one day with twenty-four one-hour subintervals, are employed to check the validity and accuracy the proposed method and compare its performance with the mentioned CSA-based methods.

Funding: This research received no external funding.

Acknowledgments: I am thankful for the contributions of professional authors and reviewers and the excellent assistant of the editorial team of Applied Sciences.

Conflicts of Interest: The author declares no conflict of interest.

\section{References}

1. Mohammadi, F.; Nazri, G.-A.; Saif, M. An Improved Droop-Based Control Strategy for MT-HVDC Systems. Electronics 2020, 9, 87. [CrossRef]

2. Mohammadi, F.; Nazri, G.-A.; Saif, M. A Bidirectional Power Charging Control Strategy for Plug-in Hybrid Electric Vehicles. Sustainability 2019, 11, 4317. [CrossRef] 
3. Mohammadi, F. Power Management Strategy in Multi-Terminal VSC-HVDC System. In Proceedings of the 4th National Conference on Applied Research in Electrical, Mechanical Computer and IT Engineering, Tehran, Iran, 4 October 2018.

4. Mohammadi, F.; Zheng, C. Stability Analysis of Electric Power System. In Proceedings of the 4th National Conference on Technology in Electrical and Computer Engineering, Tehran, Iran, 27 December 2018.

5. Mohammadi, F.; Nazri, G.A.; Saif, M. A Fast Fault Detection and Identification Approach in Power Distribution Systems. In Proceedings of the IEEE 5th International Conference on Power Generation Systems and Renewable Energy Technologies (PGSRET), Istanbul, Turkey, 26-27 August 2019.

6. Nguyen, T.T.; Mohammadi, F. Optimal Placement of TCSC for Congestion Management and Power Loss Reduction Using Multi-Objective Genetic Algorithm. Sustainability 2020, 12, 2813. [CrossRef]

7. Alvi, M.J.; Izhar, T.; Qaiser, A.A.; Kharal, H.S.; Safdar, A. Field Optimization and Electrostatic Stress Reduction of Proposed Conductor Scheme for Pliable Gas-Insulated Transmission Lines. Appl. Sci. 2019, 9, 2988. [CrossRef]

8. Mohammadi, F.; Nazri, G.-A.; Saif, M. An Improved Mixed AC/DC Power Flow Algorithm in Hybrid AC/DC Grids with MT-HVDC Systems. Appl. Sci. 2020, 10, 297. [CrossRef]

9. Shojaei, A.H.; Ghadimi, A.A.; Miveh, M.R.; Mohammadi, F.; Jurado, F. Multi-Objective Optimal Reactive Power Planning under Load Demand and Wind Power Generation Uncertainties Using $\varepsilon$-Constraint Method. Appl. Sci. 2020, 10, 2859. [CrossRef]

10. Cui, Y.; Yin, H.; Xing, Z.; Guo, X.; Zhao, S.; Wei, Y.; Li, G.; Xin, M.; Hao, C.; Lei, Q. Effect of Ionic Conductors on the Suppression of PTC and Carrier Emission of Semiconductive Composites. Appl. Sci. 2020, 10, 2915. [CrossRef]

11. Nguyen, T.T.; Pham, L.H.; Mohammadi, F.; Kien, L.C. Optimal Scheduling of Large-Scale Wind-Hydro-Thermal Systems with Fixed-Head Short-Term Model. Appl. Sci. 2020, 10, 2964. [CrossRef]

(C) 2020 by the author. Licensee MDPI, Basel, Switzerland. This article is an open access article distributed under the terms and conditions of the Creative Commons Attribution (CC BY) license (http://creativecommons.org/licenses/by/4.0/). 